\title{
Ensino religioso em escolas públicas: uma pesquisa etnográfica
}

William Soares dos Santos

Professor Adjunto do Departamento de Letras da Pontifícia Universidade católica do Rio de Janeiro - PUC-Rio.
Esta pesquisa tem como objetivos discutir 1) a problemática do ensino religioso em escolas públicas através de uma pesquisa realizada em um ambiente real de sala de aula de ensino religioso e, 2) de que forma a identidade religiosa dos alunos é trabalhada pelo professor no ambiente pesquisado (uma classe de ensino religioso de uma escola pública no Rio de Janeiro). O paradigma de pesquisa que conduz esta investigação é o de cunho interpretativista de caráter etnográfico e busca construir o significado através de investigação na sala de aula. A aula analisada neste trabalho foi registrada em áudio e transcrita horas depois. Esta pesquisa é, também, orientada pela Análise Crítica do Discurso (Fairclough, 1989, 1992) e pelas reflexões acerca do discurso e da linguagem como prática social, propostas por lingüistas e outros estudiosos da linguagem, tais como Mikhail Bakhtin ([1929] 1997), Sara Mills (1997). Os resultados indicam, entre outros aspectos, que, no modelo de aula pesquisado, não se contempla a multiplicidade de manifestações religiosas presentes na sociedade e, assim, os alunos têm acesso apenas a uma visão parcial do que seja religião, que pode entrar em choque com outras realidades religiosas que encontram fora da sala de aula.

Palavras-chave: ensino religioso, discurso religioso, identidade social e interação. 


\section{Introdução ${ }^{1}$}

A história da educação no Brasil tem suas raízes estreitamente ligadas ao ensino religioso. Criadas no início da formação do Brasil colonial, as escolas organizadas pelos padres da Companhia de Jesus visavam, principalmente, a manutenção da fé e o recrutamento de fiéis e servidores da igreja. Gradativamente, no entanto, esses objetivos deram lugar ao ensino da elite que, pouco a pouco, percebia a importância da educação na formação da hierarquia de poder na colônia. Com a ascensão, em Portugal, do Marquês de Pombal (que estava estreitamente ligado ao pensamento do Enciclopedismo francês) ocorre, em 1759, a expulsão dos Jesuítas da Companhia de Jesus, tanto de Portugal quanto de suas colônias. Com a quebra do sistema jesuítico um espaço de 13 anos foi necessário para a formulação de um novo sistema educacional, agora sob a tutela do Estado. Apesar dessa mudança a educação não foi alterada em sua essência, tendo a educação religiosa como uma de suas bases principais. Mesmo com uma maior estratificação social surgida no século XIX e a presença do príncipe regente D. João por doze anos, com a conseqüente fundação do ensino superior no Brasil, não houve modificação no sistema educacional. No séc. XX, as diversas reformas ocorridas e, a influência da revolução capitalista na expansão do ensino, além de não resolverem o problema da democratização do ensino, ainda guardaram, em sua estrutura, aspectos do ensino jesuítico (cf. Romanelli, 1991). Um desses aspectos é o ensino religioso que permanece em várias escolas da rede pública de ensino ainda nos dias de hoje.

A Lei de Diretrizes e Bases da Educação (LBD artigo 33 - Lei n 9.394 de 20 de dezembro de 1996 com redação dada pela Lei no 9475 , de 22 de julho de 1997) prevê o Ensino Religioso na Escolas da Rede Pública nos seguinte termos:

Art.33 - O Ensino Religioso, de matrícula facultativa, é parte integrante da formação básica do cidadão e constitui disciplina dos horários normais das escolas públicas de ensino fundamental, assegurado o respeito à diversidade cultural religiosa do Brasil, vedadas quaisquer formas de proselitismo.

$\S 1^{\circ}$ - Os sistemas de ensino regulamentarão os procedimentos para a definição dos conteúdos do Ensino Religioso e estabelecerão as normas para a habilitação e admissão dos professores.

$\S 2^{\circ}$ - Os sistemas de ensino ouvirão entidade civil, constituída pelas diferentes denominações religiosas, para a definição do Ensino Religioso.

A leitura da versão anterior, redigida por Darcy Ribeiro, possibilita a percepção de que o ensino religioso não deveria ser uma disciplina independente, mas ser entendida em sua interdisciplinaridade em respeito às diferentes manifestações religiosas da humanidade:

Art.33. O Ensino Religioso, de matrícula facultativa, constitui disciplina dos horários normais das Escolas Públicas de ensino fundamental, sendo oferecido, sem ônus para os cofres públicos, de acordo com as preferências manifestadas pelos alunos ou por seus responsáveis, em caráter:

I - Confessional, de acordo com opção religiosa do aluno ou de seu responsável, ministrada por professores ou orientadores religiosos preparados e credenciados pelas respectivas igrejas ou entidades religiosas; ou

II - Interconfessional, resultante de acordo entre as diversas entidades religiosas que respon- 
sabilizar-se-ão pela elaboração do respectivo programa.

Essa proposta possibilita três formas básicas de se conduzir o ensino religioso nas escolas:

1. O ensino religioso confessional - Nesta forma de condução o trabalho é feito seguindo-se uma linha religiosa específica que deixa de lado outras expressões religiosas.

2. O ensino religioso ecumênico - Nesta forma de condução o foco são as posturas éticas, e o estudo de princípios religiosos que venham ao encontro dessas posturas.

3. O ensino religioso fenomenológico - Aqui o que se busca é o estudo antropológico, comparado e, algumas vezes, crítico da religião.

A partir dessas observações tenho como objetivo nesta pesquisa discutir, 1) a problemática do ensino religioso em escolas públicas através de uma pesquisa realizada em um ambiente real de sala de aula de ensino religioso e, 2) de que forma a identidade religiosa do aluno é trabalhada pelo professor no ambiente pesquisado (uma classe de ensino religioso de uma escola pública no Brasil).

O paradigma de pesquisa que conduz esta investigação é o de cunho interpretativista uma vez que, ao contrário do paradigma positivista, a investigação não se dará através do controle de quaisquer variáveis, nem procurará demonstrar relações de causa e efeito através de qualquer mecanismo de aferição. O que se dará é uma pesquisa enfocando o espaço da sala de aula considerando que, tanto alunos quanto professor(es), dentro desse contexto, não são agentes passivos mas seres processando informações que, por sua vez, estarão sendo desenvolvidas em contexto e práticas culturais espe- cíficas com objetivos determinados (cf. Sarbin \& Kitsuse, 1994:02). Dentro do paradigma proposto a investigação terá um caráter etnográfico, uma vez que buscará construir o significado através de pesquisa no local onde as aulas ocorrem. A aula que é analisada aqui foi registrada em áudio e transcrita horas depois. Este trabalho também é orientado pela Análise Crítica do Discurso (Fairclough, 1989, 1992) e pelas reflexões acerca do discurso e da linguagem como prática social, propostas por lingüistas e outros estudiosos da linguagem, tais como Mikhail Bakhtin ([1929] 1997), Sara Mills (1997), entre outros.

\section{$2 \quad$ Identidades sociais $^{2}$}

O conceito de identidade social se refere a quem somos e a como nos posicionamos no mundo. Não obstante a multiplicidade de visões, pode-se dizer que existem duas formas básicas de se compreender a questão da identidade: a primeira é conhecida como essencialista e implica a percepção de que o ser humano herda um conjunto acabado de idéias (religiosas, sociais, políticas, etc.) que orientarão suas práticas culturais ${ }^{3}$, da mesma forma, pelo resto de sua existência.

A segunda forma de se entender o fenômeno da identidade é através de uma visão não essencialista (compreensão que adoto nesta pesquisa). Esse posicionamento leva em consideração a percepção de que a identidade é múltipla e sujeita a modificações através do tempo e dos espaços sociais em que ocupa. É tendo em conta essa percepção que Kathryn Woodward (1997:22) observa que, embora possamos nos sentir as mesmas pessoas nos diversos ambientes em que transitamos, na verdade, "estamos diferentemente posicionados pelas expec- 
tativas e limitações sociais e nos representamos de maneira diferente para os outros em cada contexto". A identidade social pode ser entendida, também, como uma posição dentro das relações sócio-econômicas e, portanto, subordinada às diversas formas de interação (que muitas vezes envolvem relações de poder) com as quais as pessoas têm que se confrontar no dia-a-dia.

Além de ser posicionada e processual, a identidade social é um fenômeno relacional (cf. De Fina, 2003:15), uma vez que constrói sua existência tendo como referência algo fora de si mesma: ela se constrói através da negação do que não se quer ser e da afirmação do que se pretende ser (Woodward, 1997:9). A constituição da(s) diferença(s) implica a formação de um conjunto de marcas simbólicas que afetam, através da exclusão ou inclusão, as condições materiais de existência dos indivíduos (idem:12).

O caráter múltiplo da identidade implica que os indivíduos podem, tendo em vista as necessidades envolvidas na interação, expor diferentes marcas identitárias, como, por exemplo, características de sua etnia, gênero, sexualidade, religiosidade, da comunidade a qual se pertence, entre outras. Esse aspecto reflete, também, o caráter contraditório da identidade, uma vez que um indivíduo pode agir de formas distintas, ou mesmo opostas, em diferentes círculos sociais. No âmbito religioso, uma pessoa pode, assim, participar regularmente de uma prática religiosa considerada hegemônica dentro da sociedade na qual vive, ao mesmo tempo em que pratica outras formas de religiosidade não hegemônicas. No Brasil, por exemplo, não é raro se encontrar pessoas que praticam o cristianismo católico ao mesmo tempo em que freqüentam rituais de religiões afro-brasileiras como a Umbanda e o Candomblé.
A identidade social se constitui através do discurso. Ao se engajarem em uma prática discursiva, os indivíduos trazem diferentes marcas de suas identidades, se construindo ao mesmo tempo em que são construídos através da interação discursiva (cf. Moita Lopes, 1998), ou seja, sendo posicionadas por um dado contexto (Hall, 1997:51). Essas posições formam os significados dentro das relações humanas, uma vez que o significado só pode ser construído socialmente ou, como coloca Bastos (2002:160),

"os indivíduos, em função de cada interação, gerenciam suas habilidades de usar diferentes variantes sociais e estilos, de selecionar determinadas estruturas sintáticas, palavras e contornos prosódicos. Por meio desses usos, das 'pistas de contextualização', os sentidos são sinalizados e interpretados pelos indivíduos em cada troca lingüística".

Essa visão implica que a identidade é algo que não possui grande relevância fora de seu contexto de produção, uma vez que ela é uma orientação ao contexto no qual estão ocorrendo as interações.

Outro aspecto da identidade social que é de grande importância é a relação entre o indivíduo e a coletividade. Se levarmos em consideração que, como coloca Wenger (1998:145), “construir uma identidade consiste em negociar os significados de nossa experiência de membros em comunidades sociais", concluímos que não pode haver uma separação real entre indivíduo e a coletividade, uma vez que, como, também, nos lembra Wenger (1998:146) "nós não podemos nos tornar humanos por nós mesmos". Nesta pesquisa, levo em consideração a identidade social como um processo que interconec- 
ta o indivíduo e a coletividade através das práticas discursivas (cf. De Fina, 2003:18).

\section{a) A questão da Identidade religiosa}

No que tange especificamente às identidades religiosas, a história mostra, basicamente, que elas têm sido formadas em termos de oposição, assim, por exemplo, na renascença (e ainda nos dias de hoje não só no Brasil mas em muitas partes do mundo) podemos constatar em diversos contextos uma oposição fortemente marcada entre católicos e protestantes. Mais recentemente entre cristianismo e outras formas de religião não cristã e, embora conceitos de religiosidade possam diferir através de períodos históricos, sociedades distintas, classes sociais, e etc., na maioria das vezes essa oposição se dá em uma evidente relação de subordinação e controle ou pela total aversão caracterizada pelo fundamentalismo (cf. Giddens, 1999: 36; Caputo, 2001:106).

\section{b) Discurso como prática social}

Uma vez que a constituição da identidade é moldada no discurso, é fundamental compreender que como observa Sara Mills (1997:11),

"o discurso não é uma coleção descorporificada de declarações, mas grupos de orações ou sentenças, que são unidas dentro de um contexto social, que são determinadas por esse contexto e que contribuem para o modo pelo qual o contexto social dá prosseguimento à sua existência”.

0 pensador russo Mikhail Bakhtin ([1929]1992:117-123) entende o discurso não simplesmente constituído de um sistema de signos estáticos, esperando para serem decodificados, mas como fazendo parte de um ato de comunicação, do diálogo, estando aí entendido a interação. Nesta pesquisa sigo a mesma linha de pensamento de Bakhtin (idem) e de Stanley Fish (1992:159) quando diz que "a interpretação não é a arte de entender, mas sim a arte de construir". E ao interpretar devemos ter em mente que "o significado não é inerente à linguagem, mas é, de fato, uma construção social" (Moita Lopes, 1995:350), um processo ativo no qual estão refletidos as ideologias (forças políticas e interesses econômicos) hegemônicas e contra-hegemônicas.

\section{A questão da Pesquisa e a especificidade da pesquisa etnográfica}

A metodologia de pesquisa empregada aqui é a de natureza interpretativista, de base etnográfica. Tratando-se, mais apropriadamente, de uma linha de micro análise etnográfica de investigação, uma vez que me deterei na análise de uma única aula.

Dentro dos Estudos da Linguagem têm-se observado a presença da pesquisa de base teórica, que privilegia um estudo reflexivo bibliográfico e a pesquisa de base empírica que privilegia a observação dos eventos no momento de sua ocorrência, podendo haver, inclusive, o uso de experimentos ou não (cf. Cavalcanti, 1990:45). As escolhas sobre a orientação do estudo a ser realizado dependerá da pesquisa, de seus objetivos e mesmo circunstâncias. A minha pesquisa, aqui, envolve a variante de base empírica.

A pesquisa de natureza empírica poderá adquirir outros desdobramentos, podendo ser uma pesquisa etnográfica, uma pesquisa-ação e etc. Dentro desses desdobramentos podemos, ainda, diferenciar entre pesquisa positivista e pesquisa interpretativista. Na pesquisa positivista existe 
uma preocupação em quantificar os dados, tirar conclusões através da percentagem das evidências. Na pesquisa interpretativista há uma maior preocupação com o caráter qualitativo dos dados, não se desqualificando, contudo, o tratamento quantitativo dos mesmos.

Andrew Cohen (1989:01) observa que na década de sessenta as pesquisas em Lingüística eram predominantemente qualitativas, ou seja baseadas em testes, experimentos e análises estatísticas. Hoje se tende a privilegiar a interação, ou seja, observar o que ocorre na sala de aula durante o processo de ensino/aprendizagem, decifrando as estratégias através da análise dos relatos verbais e visuais de alunos e professores. ${ }^{4}$

A pesquisa que trago aqui compartilha de uma postura etnográfica de pesquisa, uma vez que em um contexto social específico, tendo-se preocupação com a visão de seus participantes. Assim, o pesquisador trabalhará de modo a descobrir padrões recorrentes no ambiente estudado e investigar práticas e crenças culturais que sejam relevantes para o seu objeto de estudo. Após a coleta de dados, o pesquisador começa a avaliar e levantar questões, num diálogo com os dados visando a reflexão sobre o problema. Não se trata de uma simples descrição dos dados, mas uma problematização dos mesmos.

\section{Construção da identidade em uma aula de religião}

\section{a) Histórico e contexto da Pesquisa}

Ao desenvolver estudos sobre questões de identidade social ligada a contextos institucionais na universidade na qual desenvolvi o meu Mestrado (UFRJ), fui convidado pela coordenadora de ensino religioso do município de São João de Meriti, no estado do Rio de Janeiro, para que, unindo tanto o conhecimento sobre as religiões quanto o conhecimento a respeito de identidade, elaborasse uma palestra para os professores de ensino religioso daquele município. Essa foi a porta de entrada para que eu lhe pedisse autorização para pesquisar em uma de suas classes.

A pesquisa se deu em uma sala de aula de $3^{\text {a }}$ série primária, com alunos entre 9 e 14 anos de idade, de uma escola pública do município de São João de Meriti no Estado do Rio de Janeiro. Cheguei ao colégio meia hora antes de começar a aula para poder posicionar os gravadores de forma adequada e, também, com o objetivo de não chamar a atenção dos alunos. O que não foi possível uma vez que a professora de religião entraria em uma turma na qual outra aula já estivera em andamento, havendo, por tanto, apenas a troca de professores. Apresenteime na secretaria da escola e aguardei, por algum tempo, a chegada da professora que, até então, eu só conhecia através de uma breve conversa telefônica na qual eu expusera os motivos e objetivos da pesquisa. Quando ela chegou fomos apresentados por uma das coordenadoras do colégio. A professora de religião, então, tentou mostrar-se receptiva fazendome, no entanto, as mesmas perguntas que havia feito em nossa conversa pelo telefone, o que eu interpretei como um sinal de insegurança e de dificuldade de entender o propósito de minha presença ali.

Depois da breve conversa, nos dirigimos à sala de aula, onde havia cerca de quarenta alunos. As mesas da sala de aula estavam arrumadas de forma tradicional: enfileiradas, formavam três filas de cadeiras e mesas unidas em pares. A professora me apresentou à turma enquanto eu posicionava os gravadores, um perto da professora e outro comigo, no fundo da sala (eu tinha a autorização da professora e da coordenação para gravar a aula). 
Quando a aula chegou ao término a professora virou-se para turma e disse que eu queria falar uma coisa com eles. Fiquei surpreso porque eu não queria falar nada. Não sabia o que dizer e me saí falando da importância do dia de ação de graças (tema da aula). Quando terminamos a aula acompanhei a professora à sala dos professores. Ela me perguntou o que eu achei da turma ao que respondi que a turma me parecia muito boa. Perguntei, no entanto, se ela poderia me deixar trabalhar com alunos mais velhos. De quinta série, por exemplo, o que seria mais favorável à minha pesquisa, expliquei a ela. Ela, mais uma vez (como antes da aula $)^{5}$, me perguntou o que eu queria exatamente. Eu expliquei a ela que gostaria de ouvir os alunos falando sobre o assunto (religião) que poderia ser fomentado através do auxílio de um texto. Ela me perguntou se eu tinha algum texto, eu disse que tinha alguns artigos interessantes e que poderiam suscitar o interesse dos jovens e motivá-los à conversação. Eu lhe que poderia entregar-lhe os textos com antecedência para que ela os avaliasse e, em caso de sua aprovação, preparasse a aula. Ela me perguntou também no que consistia o meu mestrado, o que eu estudava, o que era a lingüística aplicada, para o que era a minha pesquisa e o que eu estava avaliando (não necessariamente nessa ordem e dessa maneira). Respondi-lhe que o meu principal objetivo era o de saber como os alunos viam o assunto religião e como eles estavam construindo, dentro da sala de aula, suas visões sobre religiosidade. O meu trabalho fazia parte de um curso dentro do mestrado.

Em um determinado momento a professora me perguntou qual era a minha religião, ao que lhe respondi que, naquele momento, eu não estava ligado a nenhuma e embora tendo formação protestante, sentia afinidade com o pensamento budista.
Nesse momento a professora me olhou fixamente e disse-me: "Olha mas você tem que saber que só Jesus Cristo é que salva, não é?". Pego de surpreso tentei, numa atitude familiar (cf. Bruner 1997:107), mudar o foco da questão. Mas tenho certeza que foi nesse momento que perdi a oportunidade de pesquisar naquela escola e com aquela professora. Ela me disse, então, que era evangélica de dominação Pentecostal. Disse-me ainda que tinha alguns alunos que eram Testemunhas de Jeová e que, por isso eram difíceis de lidar, principalmente no instante em que ela tocava o hino nacional. Dois dias depois ela me ligou, deixando um recado na secretária eletrônica, dando uma desculpa e pedindo para que eu continuasse a pesquisar em uma outra oportunidade. A análise que trago aqui, portanto, tem por base uma única gravação.

\section{b) Análise de dados - Na Escola Pública ${ }^{6}$}

Aula do dia 23 de novembro de 1999 - Tema: Dia de Ação de Graças.

Nessa aula, em que a professora aborda o tema "Ação de Graças", o foco recai, quase que totalmente, sobre o papel do professor, uma vez que a participação dos alunos é ínfima e quando ocorre é sempre direcionada pelas orientações da professora. Os alunos não são chamados a colaborar de forma efetiva, uma vez que eles são levados a responderem perguntas retóricas como demonstram os fragmentos abaixo:

\section{Fragmento 1}

"quê que a gente fala?"

graças é agradecimento, né?

- 01 professora: então vejam só: é agradecimento, quando a gente 


\begin{tabular}{|c|c|}
\hline > 02 & $\begin{array}{l}\text { chega em casa, que a mamãe fez } \\
\text { uma comidinha gostosa, quê que } \\
\text { a gente }\end{array}$ \\
\hline 03 & $\underline{\text { fala? }}$ \\
\hline - 04 alunos: & obrigado! \\
\hline - 05 professora: & $\begin{array}{l}\text { obrigado, né? e quando, às vezes } \\
\text { eu peço, eu estou sempre pedindo } \\
\text { um favor }\end{array}$ \\
\hline 06 & $\begin{array}{l}\text { pra vocês, né?, eu falo: leva o meu } \\
\text { gravador lá na outra sala ai, o } \\
\text { quê, } \underline{\text { ai eu }}\end{array}$ \\
\hline - 07 & falo o quê? \\
\hline 08 alunos: & obrigado! \\
\hline 09 professora: & $\begin{array}{l}\text { isso aí gente é um ato } \\
\text { de agradecimento, um } \\
\text { agradecimento né? então, quando, }\end{array}$ \\
\hline 10 & $\begin{array}{l}\text { é::, quando::, papai compra um } \\
\text { presente? o quê que a gente fala? }\end{array}$ \\
\hline - 11 alunos: & obrigado! \\
\hline 12 professora: & $\begin{array}{l}\text { obrigado né?, os homens falam } \\
\text { obrigado e as meninas falam } \\
\text { obrigada, então a }\end{array}$ \\
\hline 13 & $\begin{array}{l}\text { palavra é masculino e feminino } \\
\text { né? }\end{array}$ \\
\hline
\end{tabular}

Fragmento 2

\begin{tabular}{ll}
\hline \multicolumn{2}{c}{ “que dia é hoje?”, } \\
\hline 01 professora: & $\begin{array}{l}\text { por mais esse dia, não é? então } \\
\text { nós devemos, é... sempre } \\
\text { agradecer, ó, existe }\end{array}$ \\
\hline 02 & $\begin{array}{l}\text { um dia reservado, não é? pra:: é } \\
\text { o dia de ação de graça, é toda a } \\
\text { quinta- }\end{array}$ \\
\hline 03 & $\begin{array}{l}\text { feira::, quinta-feira, é::, é a última } \\
\text { quinta-feira, a última, né? do::, } \\
\text { é::, de }\end{array}$ \\
\hline & $\begin{array}{l}\text { novembro, este ano vai cair no dia } \\
25 \text { de novembro, né? hoje, que dia } \\
\text { é hoje? }\end{array}$ \\
\hline
\end{tabular}

05 alunos: vinte e três!

\section{Fragmento 3}

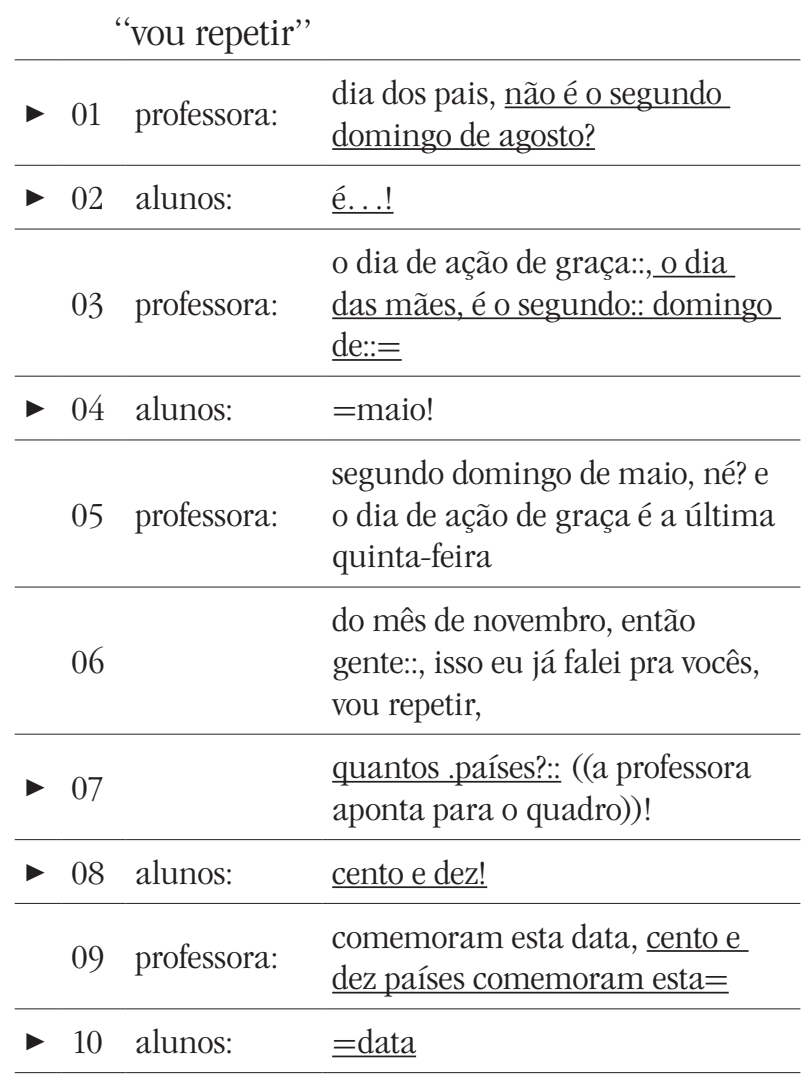

Durante todo o percurso da aula a professora segue esse modelo de pergunta/resposta no qual a resposta está imbuída na pergunta ou a resposta se restringe na repetição do que a professora acabara de falar. Entendi o seu comportamento como reflexo de sua visão de aula como sendo, principalmente, controle do turno (e de turma). Isso fica claro em um momento no qual as crianças começam a falar e a professora pede para que eu desligue o gravador. Li sua atitude como sendo a de alguém preocupada em estar sendo testada em suas habilidades, em seu desempenho de dominar a turma. Pude observar também que toda a aula foi construída em torno de atividades, deixando mesmo transpassar uma percepção de aula como um conjunto de estratégias fixas, ou fossilizadas, que evitam o comprometimento do professor através do diálogo. 
Outro ponto bastante significativo que pude observar é o fato de que, em sendo a aula de religião, o foco religioso se dilui em outras questões. Vejamos, por exemplo, os fragmentos abaixo:

\section{Fragmento 4}

\begin{tabular}{|c|c|c|}
\hline - 01 & professora: & $\begin{array}{c}\text { que figura é essa? brasil!? nós } \\
\text { devemos, é... agradecer a deus } \\
\text { pelo nosso país, }\end{array}$ \\
\hline 02 & & $\begin{array}{c}\text { pelo brasil, né? aqui::, vamos colá } \\
\text { o brasil aqui (dentro do) mural, } \\
\text { colá o brasil }\end{array}$ \\
\hline 03 & & $\begin{array}{c}\text { aqui ó, todo mundo vai agradecer } \\
\text { a deus pelo brasil, esse país } \\
\text { enorme, nosso }\end{array}$ \\
\hline 04 & & $\begin{array}{l}\text { brasil tem mais de oito milhões } \\
\text { e meio de (...), sabiam? o brasil } \\
\text { tem mais de }\end{array}$ \\
\hline 05 & & $\begin{array}{l}\text { oito milhões e meio, ele tem um } \\
\text { clima tropical, clima gostoso, ele::, } \\
\text { aqui no }\end{array}$ \\
\hline 06 & & $\begin{array}{l}\text { brasil nós temos tu-, nós temos } \\
\text { oceano, nós temos planície, nós } \\
\text { temos planalto, }\end{array}$ \\
\hline • 07 & & $\begin{array}{c}\text { temos tudo ((devido ao som } \\
\text { das crianças falando, a voz da } \\
\text { professora, aumenta }\end{array}$ \\
\hline • 08 & & $\begin{array}{l}\text { gradualmente)), temos, o brasil é } \\
\text { muito bonito, alá o oceano como } \\
\text { é que é }\end{array}$ \\
\hline • 09 & & $\begin{array}{l}\text { grande ó, e o brasil::, quantos } \\
\text { estados tem o brasil? falei no dia } \\
\text { da bandeira, }\end{array}$ \\
\hline$>10$ & alunos: & vinte e seis! vinte e seis. \\
\hline - 11 & professora: & ahh! vinte e seis, e distrito federal? \\
\hline - 12 & alunos: & $\begin{array}{l}\text { ((alguns alunos falam } \\
\text { seguidamente)): } \underline{\mathrm{um} !}\end{array}$ \\
\hline$>$ & professora: & $\begin{array}{l}\text { um distrito federal, né? então } \\
\text { vocês tão bem lembrados }\end{array}$ \\
\hline
\end{tabular}

\section{Fragmento 5}

"quais são as cores da bandeira do brasil?"

\begin{tabular}{ccc}
\hline 01 & professora: & $\begin{array}{c}\text { a bandeira do Brasil, quais são } \\
\text { as cores da bandeira? vai colando } \\
\text { lá ((se }\end{array}$ \\
\hline 02 & & dirigindo à aluna com a figura)) \\
\hline 03 & alunos: & verde, amarelo, azul e branco! \\
\hline 04 & professora: & o quê no:., o verde simboliza? \\
\hline 05 & alunos: & as matas! \\
\hline 06 & professora: & e o amarelo? \\
\hline 07 & alunos: & o ouro! \\
\hline 08 & professora: & e o azul? \\
\hline 09 & alunos: & o céu \\
\hline 10 & professora: & e o branco? \\
\hline 11 & alunos: & a paz! \\
\hline
\end{tabular}

\section{Fragmento 6}

"é muito bom ter amigo"

\begin{tabular}{cc}
\hline 01 professora: & $\begin{array}{c}\text { é muito bom ter amigo, eu tenho } \\
\text { muitos amigos graças a deus, eu } \\
\text { tenho muitos }\end{array}$ \\
\hline 02 & $\begin{array}{c}\text { amigos, ó, vejam só: outro dia::, } \\
\text { outro dia eu fui numa escola } \\
\text { lon::ge, lon:::ge, }\end{array}$ \\
\hline 03 & $\begin{array}{c}\text { ai eu cheguei toda cabisbaixa, } \\
\text { toda cheia de vergonha, ai } \\
\text { quando eu tava no }\end{array}$ \\
\hline 04 & $\begin{array}{c}\text { portão assim, ai uma menina } \\
\text { (falou lá de dentro), professora! a } \\
\text { eu falei comigo, }\end{array}$ \\
\hline 05 & $\begin{array}{c}\text { "opa! já tem uma pessoa ali, né? } \\
\text { que me conhece e falou o meu } \\
\text { nome com }\end{array}$ \\
\hline 06 & $\begin{array}{c}\text { muito carinho", então nós temos } \\
\text { que cultivar a amizade, porque a }\end{array}$ \\
\hline 07 & amizade \\
\hline 0
\end{tabular}


No que tange especificamente à religião, os exemplos acima sugerem que, embora trabalhando um tema que pode muito bem ser considerado como religioso, a professora não trata o tópico em seu aspecto religioso, mas com uma conotação de moral e cívica. Percebe-se um desejo muito forte de despertar nos alunos o sentimento patriótico através da exaltação de símbolos nacionais, de enfoque em datas históricas e riquezas naturais do país, ainda o desejo de direcionar o caráter do aluno para um comportamento moral bem aceito pela sociedade, como o companheirismo, que ela desenvolve na pequena narrativa trazida no sexto fragmento. Esse era o objetivo de disciplinas como Moral e Cívica e OSPB (Organização social e política do Brasil) que faziam parte do currículo das escolas durante o regime militar. A aula não possibilita visões do que seja o cristianismo, corrente religiosa na qual a data tema da aula se insere, nem procura correlacionar esta data com outras religiões, por exemplo, saber se outras religiões comemoram ou não essa data.

Esse posicionamento enraíza a idéia de uma única religião, de uma única cultura, criando base para a formação "do que é chamado de bom senso, um sistema de crenças assumidas como partilhadas por todos os membros de uma cultura" (Linde 1993:12), tornando difícil nos darmos conta delas, moldando a nossa identidade e, às vezes, limitando o nosso mundo e as nossas escolhas. Crenças de senso comum são tão óbvias e transparentes para os membros de uma dada cultura que eles têm dificuldade de percebê-las como pressuposições. Dessa forma, o aluno sai da escola com uma visão parcial do que seja religião, que muitas vezes entra em choque quando esse aluno, fora da sala de aula, se vê em contato com outras realidades religiosas. Além disso a aula de cunho moralizante, de ensino do que seria o "certo" e o "errado" não discute temas como o da solidariedade, respeito ao próximo e outros correlacionados.

Esse modelo de aula vai, inclusive, de encontro aos objetivos explicitados nos parâmetros do município ao que diz respeito ao ensino religioso que seriam o de "fundamentar, de forma construtiva o respeito pessoal e coletivo". Para que esses objetivos sejam alcançados entendo que seria necessária a implementação do que podemos chamar de um objetivo curricular que, de forma realista, leve em consideração o aluno, o sistema educacional e a função social do ensino religioso (cf. Freire, 1998:50).

\section{5 Últimas considerações}

A análise dos dados trazidos aqui aponta para uma ausência, na aula implementada pela professora, de uma "atualização, na sala de aula, da consciência crítica dos processos de construção social de significados, que nos constroem e que constroem os outros e o mundo a nossa volta" (Moita Lopes 1997:19). Através dessa consciência crítica é possível realizar um trabalho no qual se privilegiam outras vozes religiosas, evitando um conflito, presente ou futuro, no qual o aluno pode, por exemplo, ser compelido a fazer parte de uma prática religiosa hegemônica, sendo participante de outra(s) prática(s) religiosa(s) considerada(s) não hegemônica(s), para não se sentir à margem da sociedade. O educador pode, ainda, desenvolver um trabalho no qual o aluno perceba as várias expressões religiosas de seu meio social.

Um dos principais problemas desta pesquisa é que se tornou muito difícil obter uma visão mais precisa das idéias dos alunos participantes da interação. Também senti falta de pesquisar em uma sala de aula com alunos mais velhos, de quinta série, por 
exemplo, e de uma pesquisa mais extensa uma vez que o campo me foi fechado, como demonstrei no histórico da pesquisa, por falta de compreensão do processo de pesquisa por parte da professora. Essa incompreensão, por sua vez, é o reflexo de uma formação "indiretamente voltada para o ensino e a ausência de tradição de pesquisa" (Cavalcanti \& Moita Lopes, 1991:133). Dessa forma, esse posicionamento não é de responsabilidade exclusiva da professora, mas de um sistema educacional que tende a se pautar tão somente na repetição de técnicas de ensino. Talvez a professora temesse a crítica e não quis se expor a isso. A esse respeito cabe a nós, pesquisadores, sempre refletirmos sobre a difícil tarefa da pesquisa, que precisa apontar aspectos a serem reconsiderados, ao mesmo tempo em que deve buscar ter consideração e respeito pelo campo pesquisado e pelas pessoas que nos abrem as suas portas.

Considero que, por se tratar de um espaço que deveria, em primeira instância, ser democrático ${ }^{7}$ e, se existe aula de religião neste espaço, a escola pública deveria dar vazão às diferentes (ou pelo menos as principais) correntes religiosas presentes na sociedade que a circunscreve, não de forma a privilegiar uma ou outra, mas de modo que o aluno tenha acesso a outras realidades e pensamentos que não o seu.

\section{Religious teaching in public schools: an ethnographic research.}

This paper aims at discussing 1) the problematic of teaching religion in public schools through a research held in a real environment of a class of religious teaching and, 2) how the religious identity of the students is worked by the teacher in this particular setting (a class of religious teaching in a Brazilian public school). The research paradigm that conducts this investigation is of an interpretative approach of ethnographic character and the meaning is constructed through an investigation in a classroom. The class investigated here was audio registered and transcribed few hours later. This work is also guided by the Critical Discourse Analysis (Fairclough, 1989, 1992) and by the reflections about discourse and about language as a social practice, proposed by linguists and other language thinkers as Mikhail Bakhtin ([1929] 1997), Sara Mills (1997) and others. The results point to the perception that, in the researched class, the multiplicity of religious practices present in society is not considered and, thus, the students have access only to a partial view of what religion is, which can be in conflict with other religious manifestations they can face out of school.

Key words: religious teaching, religious discourse, social identity and interaction.

\section{Notas}

1 Agradeço à Prof. Dra. Adrianne Ogêda Guedes do Departamento de Educação da PUC-Rio por sua leitura e comentários.

2 Fui despertado para as questões de identidade quando, em 1998, tive a oportunidade de trabalhar junto ao Projeto Identidade, dirigido e orientado pelo Prof. Dr. Luiz Paulo da Moita Lopes. Este projeto, ligado ao departamento de Letras Anglo-Germânicas da Faculdade de Letras da UFRJ, tinha, então, como finalidade, pesquisar e analisar os processos interacionais em salas de aulas específicas, dando enfoque à importância do papel dos significados construídos em sala de aula na construção da identidade social dos participantes em relação a outros significados construídos fora da sala de aula, entre outros desdobramentos. Foi ali que, observando que as identidades são construídas no discurso, é que pude perceber a importância da construção da identidade como formadora do papel que cada 
indivíduo irá desempenhar dentro da sociedade e, também, o papel relevante de certos agentes (como o professor, meios de comunicação e etc.) na formação da identidade do outro.

3 Para uma discussão mais abrangente sobre a noção de cultura recomendo a leitura, dentre outros trabalhos, do texto "the concept(s) of Culture" de William H. Sewell, da primeira parte (Taking Bearings) da tese de doutorado de Silvia de Barros Abbud intitulada The Issue of Culture in EFL Lessons in Brazil: An Ethnographic Investigation, que pode ser encontrada no banco de teses da Faculdade de Letras da UFRJ e do livro de Clifford Geertz A interpretação das culturas.

4 Digo "tende-se a privilegiar" porque a Lingüística permite o uso das mais diversas abordagens de pesquisa podendo, inclusive, haver discordância entre elas. É interessante notar, a esse propósito que, como observa Thiollent (1998:21), "hoje em dia não existe um padrão de cientificidade universal", o importante é não deixar de lado a preocupação científica.

5 Aqui, note-se, já certa insegurança da professora. Ligada, talvez, ao medo de estar sendo avaliada.

6 Toda a transcrição de dados é realizada com letras minúsculas. Faço isso para ressaltar a importância de todos os elementos da fala. Assumo a posição teórica de que, ao não utilizar letra maiúscula, evito por em relevo um elemento em detrimento de outro. $\mathrm{Na}$ primeira coluna das transcrições utilizarei um símbolo - para ressaltar momentos importantes da fala dos narradores, porém, nem sempre farei referência direta a esses momentos na análise.

7 Diferente do que acontece quando os pais escolhem (ou podem) inscrever seus filhos em escolas de caráter religioso como as escolas protestantes, judaicas ou católicas, o que implica a aceitação do direcionamento religioso da escola.

\section{Referências bibliográficas:}

\author{
ABBUD, Silvia M. de Barros. (1995). The Issue of \\ Culture in EFL Lessons in Brazil: An Ethnografic \\ Investigation. University of London. Phd Thesis.
}

BASTOS, Liliana Cabral (2002). "Construção e reconstrução de identidade em interações de trabalho”. In: Souza e Silva, Cecília e Daniel Faita (orgs.). Linguagem e Trabalho. Construção de objetos de análise no Brasil e na França. São Paulo, Cortez Editora, p.159-173.

BAKHTIN, M./VOLOSHINOV. ([1929], 1997). Marxismo e Filosofia da Linguagem. Tradução de Michel Lahud e Yara Frateschi Vieira, com colaboração de Lúcia Teixeira Wisnik e Carlos Henrique D. Chagas Cruz. São Paulo: Hucitec.

BRUNER, Jerome. (1997). Atos de Significação. Tradução de Sandra Costa. Porto Alegre. Artes Médicas.

CAPUTO, John D. (2001). On Religion. London and New York: Routledge.

CAVALCANTI, Marilda C. (1990). "Metodologia de Pesquisa em Lingüística Aplicada”. In: Intercâmbio, 1, p.41-48.

CAVALCANTI, Marilda C. \& MOITA LOPES, Luiz Paulo da. (1991). "Implementação de Pesquisa na Sala de Aula de Línguas no Contexto Brasileiro". Trabalbos em Lingüística Aplicada. 17, p.: 132-144.

COHEN, Andrew. (1989). "Metodologia de Pesquisa em Lingüística Aplicada: Mudanças e Perspectivas”. Trabalhos em Lingüística Aplicada, 13, p. 1-13.

DE FINA, Anna (2003). Identity in Narrative: $a$ Study of Immigrant Discourse. Philadelphia: John Benjamins.

FAIRCLOUGH, Norman. (1992). Language and Power. Londres: Longman.

(1992) Discourse and Social Change. Cambridge. Polity Press.

FISH, Stanley. (1992). "Como reconhecer um poema ao vê-lo”. In Palavra, no 1, p. 156-165.

FREIRE, Alice Maria da Fonseca. (1998). "Aquisição de Português como segunda língua: uma proposta de currículo”. Espaço (Periódico do INES), junho.

GEERTZ, Clifford (1989). A interpretação das culturas. Trad. Gilberto Velho. Rio de Janeiro: LTC. 
GIDDENS, Antony (2003). Runaway World. New York: Routledge.

HALL, Stuart (1997). "Cultural Identity and Diaspora". In: WOODWARD, Kathryn (org.). Identity and Difference. London, Thousand Oaks and New Delhi: Sage Publications in association with The Open University, 51-8.

MILLS, Sara. (1997). Discourse. London \& New York. Routledge.

MOITA LOPES, Luiz Paulo da. (1995). "What is this class about? Topic Formulation in a L1 Reading Comprehension Classroom. In COOK, G. \& SEIDELHOFEN, B. (eds). Principle and Practice in Applied Linguistics. Oxford. Oxford University Press.

(1997). (Re-)construção das Identidades Sociais de Gênero e orientação Sexual no Discurso da Sala de aula de Línguas. Trabalho apresentado no XIV ENPULI, na UFMG, Belo Horizonte, mimeo.
ROMANELLI, Otaíza de Oliveira. (1991). História da Educação no Brasil. Petrópolis. Vozes.

SARBIN, T. R. \& KITSUSE, J. L. (1994). "A Prologue to Constructing the Social". In: Constructing the Social. London: Sage.

SEWELL, William H. Jr. (1999). "The Concept(s) of Culture". In: Beyond the Cultural Turn: New Directions in the Study of Society and Cultural. Edited by Victoria E. Bonell: University of California Press.

THIOLLENT, Michel. (1998). Metodologia da PesquisaAção. $8^{\circ}$ ed. São Paulo. Cortez editora.

WENGER, E. (1998). Communities of Practice: Learning, Meaning and Identity. USA: Cambridge University Press.

WOODWARD, K. (1997). "Introduction". In: Identity and Difference. London, Thousand Oaks and New Delhi. Sage Publications / The Open University. recebido em jul. 2009 / aprovado em ago. 2009

Para referenciar este texto:

SANTOS, W. S. dos. Ensino religioso em escolas públicas: uma pesquisa etnográfica. Dialogia, São Paulo, v. 8, n. 1, p. 109-121, 2009. 
